\title{
Predicting energy absorption in a foam-filled thin-walled aluminum tube based on experimentally determined strengthening coefficient
}

\author{
Halit Kavi ${ }^{\text {a }}$, A. Kaan Toksoy ${ }^{\text {a }}$, Mustafa Guden ${ }^{\text {a,b,* }}$ \\ ${ }^{a}$ Department of Mechanical Engineering, Izmir Institute of Technology, Gülbahçe Köyü, Urla, Izmir, Turkey \\ ${ }^{\mathrm{b}}$ Center for Materials Research, Izmir Institute of Technology, Gülbahçe Köyü, Urla, Izmir, Turkey
}

Received 19 April 2004; accepted 29 October 2004

Available online 10 December 2004

\begin{abstract}
The energy absorption in a foam-filled thin-walled circular Al tube was investigated based on the experimentally determined strengthening coefficient of filling using $\mathrm{Al}$ and polystyrene closed-cell foams with three different densities. Foam filling was found to change the deformation mode of tube from diamond (empty tube) into concertina, regardless the foam type and density used. Although foam filling resulted in higher energy absorption than the sum of the energy absorptions of the tube alone and foam alone, it was not effective in increasing the specific energy than simply thickening the tube wall. It was shown that for efficient foam filling an appropriate foam-tube combination must be selected by taking into account the magnitude of strengthening coefficient of foam filling and the foam filler plateau load.
\end{abstract}

(C) 2004 Elsevier Ltd. All rights reserved.

Keywords: Foam filled tube; Strengthening coefficient; Compression test; Energy absorption

\section{Introduction}

Columnar structures including square and circular metal tubes crush under compressive loads nearly at a constant load, resulting in relatively high energy absorption efficiency. It has been shown that when aluminum and steel metal tubes are filled with light weight core materials such as Al closed cell foams, there exists an interaction effect between tube wall and foam filler [16]. The crushing loads of foam filled tubes are therefore found to be higher than the sum of the crushing loads of foam (alone) and tube (alone) mainly due to this effect. Studies on crushing behavior of Al honeycomb and foam filled box columns also showed that the effect of \footnotetext{
6505.

* Corresponding author. Tel.: +90 232498 6595; fax: +90 232498

E-mail address: mustafaguden@iyte.edu.tr (M. Guden).
}

filling on the column crushing load was similar when the strong axis of honeycomb was through and normal to the compression axis, proving that both axial and transverse strength of the filler were effective in increasing the crushing load of filled tube [6]. Hannsen et al. $[2,4]$ developed an equation for the average crushing load of foam filled $\left(P_{\mathrm{af}}\right)$ columns by including contributions of the average crushing load of empty tube $\left(P_{\mathrm{ae}}\right)$, foam plateau stress $\left(\sigma_{\mathrm{pl}}\right)$ and interaction effect. The equation was found to be well agreed with experimental results and is given as

$P_{\mathrm{af}}=P_{\mathrm{ae}}+\sigma_{\mathrm{pl}} b^{2}+C_{\mathrm{avg}} \sqrt{\sigma_{\mathrm{pl}} \sigma_{\mathrm{y}}} b t$,

where $C_{\text {avg }}, \sigma_{\mathrm{y}}, b$ and $t$ are the dimensionless constant which is directly related to the interaction effect, yield strength of the tube material and tube width and thickness, respectively. The second term of the right hand side of the Eq. (1) accounts for the axial compression of the 
foam and the last term for the interaction effect. Santosa et al. [7], based on Finite Element Modelling (FEM) results, proposed the following equation for the average crushing load of foam filled square tubes of length $b$

$P_{\mathrm{af}}=P_{\mathrm{ae}}+C \sigma_{\mathrm{pl}} b^{2}$.

The constant $C$ in Eq. (2) is considered to be the strengthening coefficient of foam filling. The study of Santosa et al. [7] has also shown that the use of adhesive, although resulting in a relatively small increase in the total weight of the tube, $<16 \%$, raised the crushing load of tube by as much as the foam crushing load.

Studies on the crushing behavior of foam filled tubes were particularly aimed at determining the effect of foam filling on the average crushing load and the specific energy absorption [1,2,5,8-10]. In designing with foam filled tubes, knowledge of upper and lower limits of the strengthening may be however required for the accurate prediction of the specific energy absorption of any tube-filler combination. The method used in this study to predict the energy absorption in foam filled tubes was based on the experimentally determined strengthening coefficient of foam filling. For this purpose, relatively high and low density foams of $\mathrm{Al}$ and polystyrene closed cell foams were used to fill a circular thin-walled Al tube. The energy absorption in Al foam filled tubes was then predicted as function of tube mass for the fillers of higher densities. The predicted energy absorption was finally compared with that of wall-thickening of empty tube in order to analyze the efficiency of foam filling.

\section{Materials and testing methods}

The deep drawn aluminum tube studied $(99 \% \mathrm{Al})$ was $25 \mathrm{~mm}$ in diameter with a wall thickness of $0.29 \mathrm{~mm}$. Tubes filled with polystyrene foams were $40 \mathrm{~mm}$ in length, while tubes filled with aluminum foams were $27 \mathrm{~mm}$ in length. Chosen tube lengths were mainly dictated by the thickness of foam filler. Extruded polystyrene foam plates of $50 \mathrm{~mm}$ thick were received from IZOCAM Company of Turkey with three different densities; $0.021,0.027$ and $0.032 \mathrm{~g} \mathrm{~cm}^{-3}$. The dense skin layers of foam plates, presumably $5 \mathrm{~mm}$ thick, were removed. Al closed cell foams with three different densities; $0.27,0.35$ and $0.43 \mathrm{~g} \mathrm{~cm}^{-3}$ were prepared in house using the foaming from powder compacts techniques patented by Fraunhofer Resource Center of Germany [11]. In this process, dense Al compacts contained $\mathrm{TiH}_{2}$ blowing agent was heated above the melting temperature of $\mathrm{Al}, 750{ }^{\circ} \mathrm{C}$. The foaming was conducted inside a rectangular mold having $80 \mathrm{~mm}$ width and $40 \mathrm{~mm}$ thickness. The thickness of prepared foams was machined down to $27 \mathrm{~mm}$ in order to remove the skin layers. Detailed information on the foam preparation

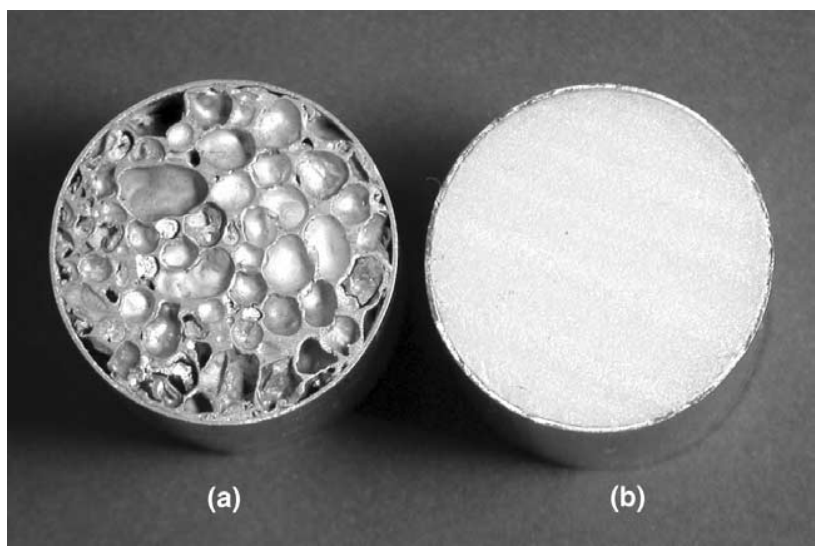

Fig. 1. (a) Al and (b) polystyrene foam filled Al tubes.

method and $\mathrm{Al}$ powder used is given in another study [12]. Cylindrical Al and polystyrene foam cores were prepared by core drilling through thickness direction of foam plates using water as the cooling agent. The inner diameter of the tube was almost the same as the diameter of the foam core so that foam samples fitted tightly inside the tubes (see Fig. 1(a) and (b)). The weights and dimensions of tubes and fillers were measured before and after filling. Quasi-static compression tests on empty and filled tubes and foam samples were conducted using a displacement controlled SHIMADZU AG-I universal testing machine with a displacement rate of $0.04 \mathrm{~mm} \mathrm{~s}^{-1}$. Polystyrene cubic foam samples of $50 \mathrm{~mm}$ thick were tested in accordance with ASTM D1621-91. Al foam compression test samples were $27 \mathrm{~mm}$ in thickness and $40 \mathrm{~mm}$ in width and length. Finally, at least 5 tests were conducted for each foam sample.

Corresponding average crushing loads $\left(P_{\mathrm{a}}\right)$ of the tested tubes were calculated using the following relation:

$P_{\mathrm{a}}=\frac{\int P \mathrm{~d} \delta}{\delta}$,

where $P$ and $\delta$ are the load and displacement, respectively.

\section{Results and discussions}

\subsection{Filler materials}

Fig. 2(a) shows the compression nominal stressstrain curves of polystyrene foams tested through thickness $(R)$ direction for three different densities. The plateau stresses are determined in the initial flat regions of the stress-strain curves as marked with arrows in Fig. 2(a). It is found that although, plateau stresses through width $(W)$ and length directions of as-received foam plates are very similar for each density, the foam shows higher plateau stresses in the $R$ direction as 

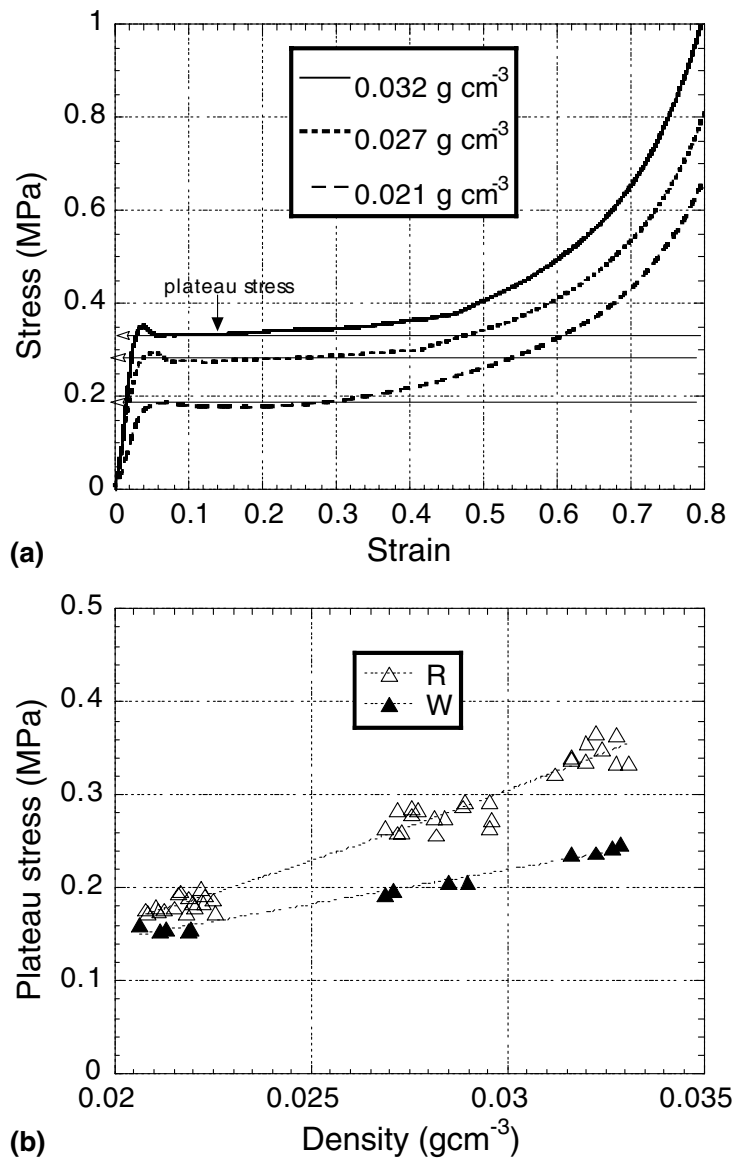

Fig. 2. (a) Typical nominal compression stress-strain curves of polystyrene foams tested through thickness. (b) Variation of plateau stress with foam density through thickness $(R)$ and width $(W)$ directions.

Table 1

Plateau stress and average plateau stress values of polystyrene foams through $R$ and $W$ directions

\begin{tabular}{llll}
\hline $\begin{array}{l}\text { Foam density } \\
\left(\mathrm{g} \mathrm{cm}^{-3}\right)\end{array}$ & $\begin{array}{l}\text { Through thickness } \\
\text { plateau stress } \\
(\mathrm{MPa})\end{array}$ & $\begin{array}{l}\text { Through width } \\
\text { plateau stress } \\
(\mathrm{MPa})\end{array}$ & $\begin{array}{l}\text { Average } \\
\text { plateau } \\
\text { stress (MPa) }\end{array}$ \\
\hline 0.021 & 0.184 & 0.156 & 0.170 \\
0.028 & 0.275 & 0.191 & 0.233 \\
0.032 & 0.345 & 0.223 & 0.284 \\
\hline
\end{tabular}

depicted in Fig. 2(b). An average plateau stress is therefore calculated for each foam density and listed in Table 1 together with corresponding plateau stresses in $R$ and $W$ directions.

Al foams tested through 3-different directions showed nearly the same compression stress-strain curves. Fig. 3 shows the typical compression stress-strain curves of $\mathrm{Al}$ foams tested through thickness direction. Again, the plateau stresses are determined from the initial flat regions of the curves as marked with arrows in Fig. 3 and the corresponding average plateau stress values of $\mathrm{Al}$ foams

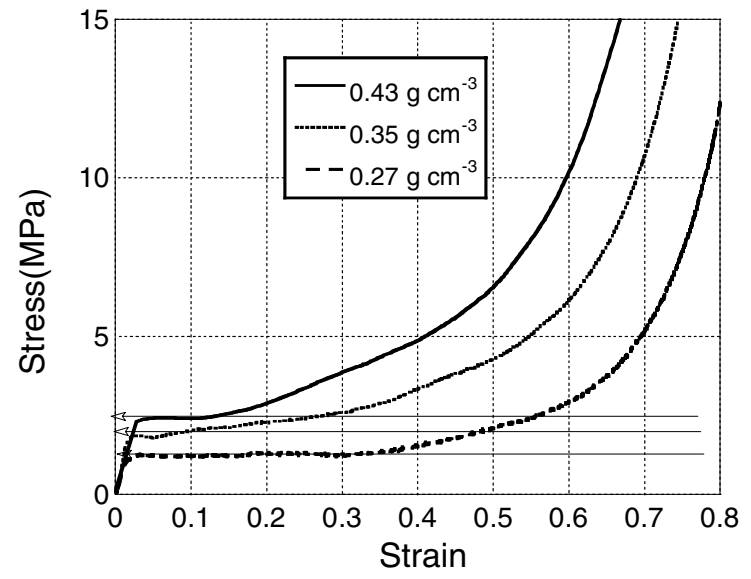

Fig. 3. Typical compression stress-strain curves $\mathrm{Al}$ foams.

Table 2

Average plateau stress values of $\mathrm{Al}$ foams

\begin{tabular}{ll}
\hline Foam density $\left(\mathrm{g} \mathrm{cm}^{-3}\right)$ & Plateau stress $(\mathrm{MPa})$ \\
\hline 0.27 & 1.24 \\
0.35 & 1.96 \\
0.43 & 2.44 \\
\hline
\end{tabular}

are listed in Table 2. The plateau stress $\left(\sigma_{\mathrm{pl}}\right)$ is found to be well fitted with power-law of strengthening equation

$\sigma_{\mathrm{pl}}=K \rho^{n}(\mathrm{MPa})$,

where $K$ and $n$ are constants and $\rho$ is the foam density in $\mathrm{g} \mathrm{cm}^{-3}$. The values of $K$ and $n$ are $\sim 8.63(\mathrm{MPa})$ and $\sim 1.47$, respectively.

\subsection{Empty tubes}

In order to determine the effect of tube length on the compression behavior, empty tubes of various lengths were tested. The compression load-displacement curves of empty tubes of 27, 40 and $50 \mathrm{~mm}$ long are shown in Fig. 4(a). No significant effect of tube length on the average crushing load of empty tubes is also seen in Fig. 4(b), except shorter tubes lock-up at lower displacements as marked with arrows in Fig. 4(a). Folding in empty tubes always started at one of the ends of tube. Although the first fold formed in axisymmetric mode, the deformation mode reverted into progressive asymmetric folding (diamond), see Fig. 5(a) and (b). A similar deformation behavior was also previously observed in empty $\mathrm{Al}$ tubes and it was proposed to be due to the influence of the axisymmetric trigger on the first fold [2]. Totally 11-12, 8-9 and 5-6 diamond folds formed in 50, 40 and $27 \mathrm{~mm}$ long $\mathrm{Al}$ empty tubes, respectively. 

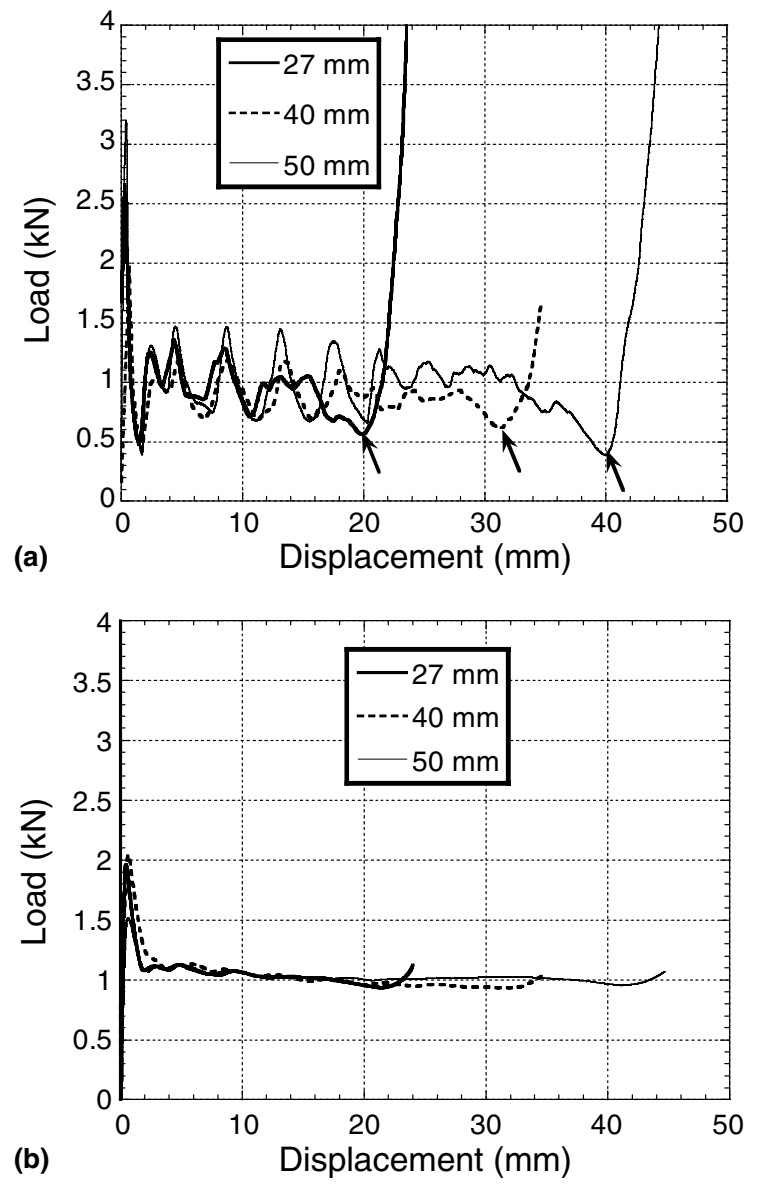

Fig. 4. (a) Load-displacement. (b) Average load-displacement curves of empty tubes of various lengths.

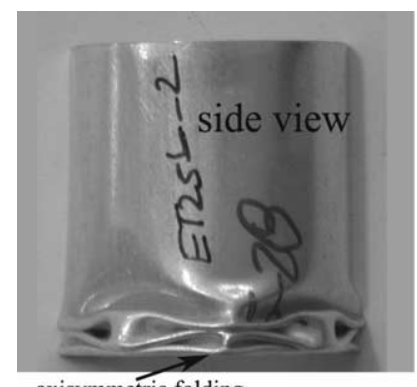

axisymmetric folding

(a)

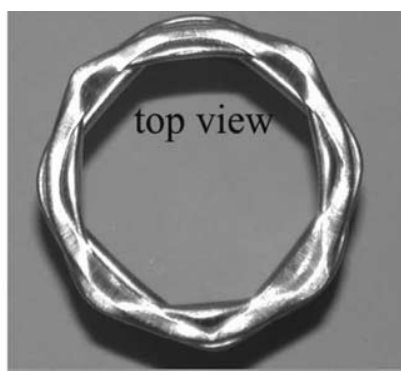

(b)
Fig. 5. Partially crushed empty tube pictures: (a) side view, showing the first axisymmetric fold and diamond mode of deformation; (b) top view.

\subsection{Foam filled tubes}

The deformation mode of filled tubes was progressive axisymmetric (concertina) for the studied $\mathrm{Al}$ and polystyrene foam densities (Fig. 6(a) and (b)). Typical compression load-displacement curves of the foam filled tubes at different filler densities and empty tube are shown in Fig. 7. Since the aluminum foam filled tubes were shorter, they lock-up at lower displacements as

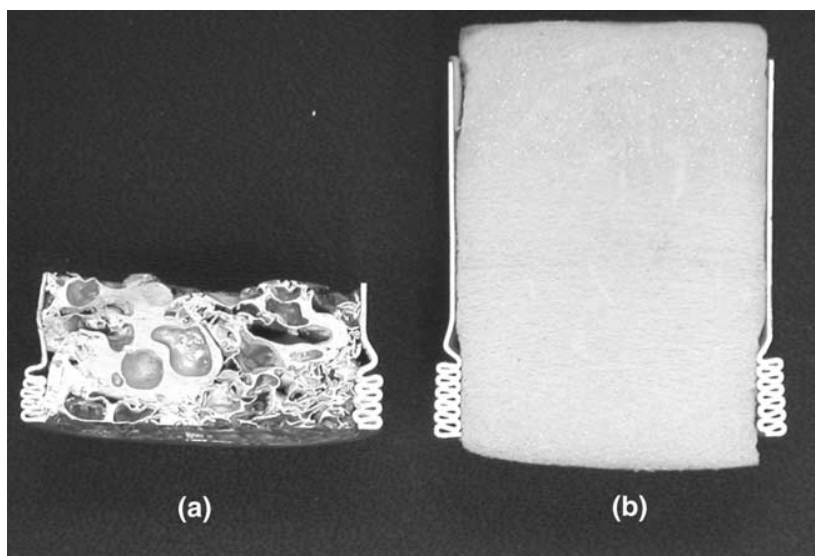

Fig. 6. Cross-sections of the partially crushed (a) Al foam $(0.27$ $\left.\mathrm{g} \mathrm{cm}^{-3}\right)$; (b) polystyrene foam $\left(0.032 \mathrm{~g} \mathrm{~cm}^{-3}\right)$ filled tubes, deforming in concertina mode.

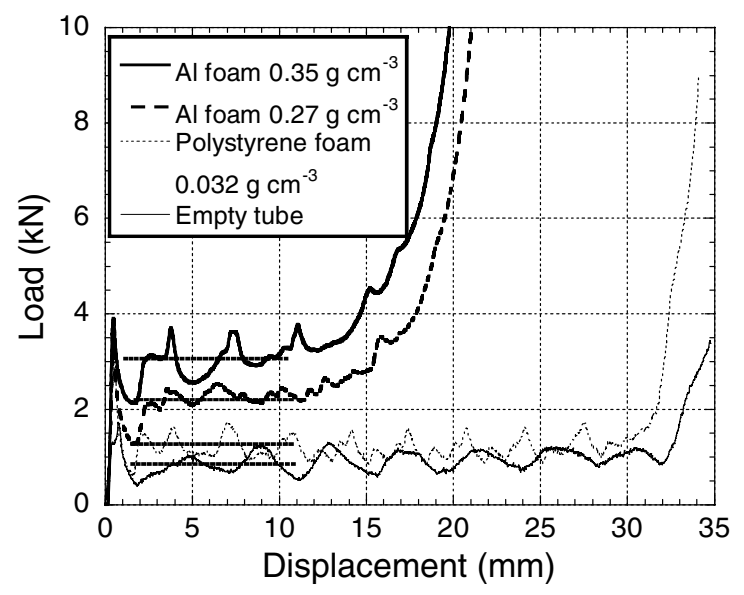

Fig. 7. Load-displacement curves of foam filled and empty tubes, dotted lines show average crushing loads.

seen in Fig. 7. Besides foam filling changes the deformation mode of empty tube, it also results in interaction effect between tube wall and foam filler. This is shown in Fig. 8 for the $\mathrm{Al}$ foam $\left(0.27 \mathrm{~g} \mathrm{~cm}^{-3}\right)$ filled tube. The load values of the filled tube shown in this figure is higher

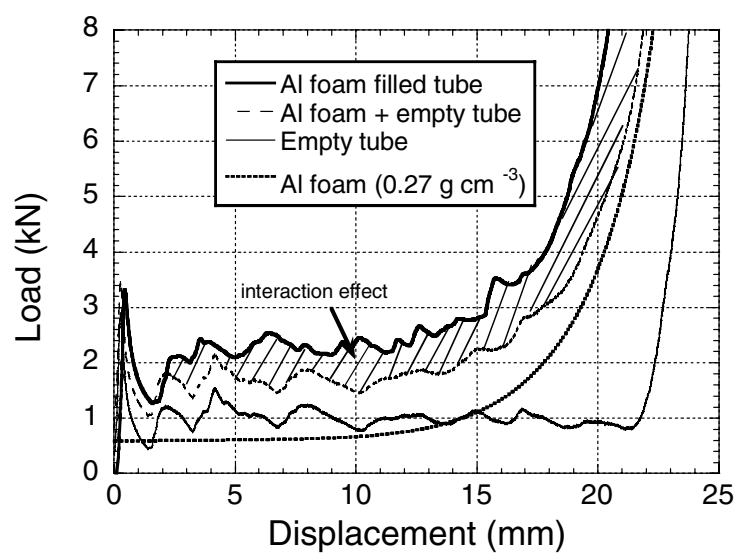

Fig. 8. Interaction effect in $\mathrm{Al}$ foam $\left(0.27 \mathrm{~g} \mathrm{~cm}^{-3}\right)$ filled tube. 


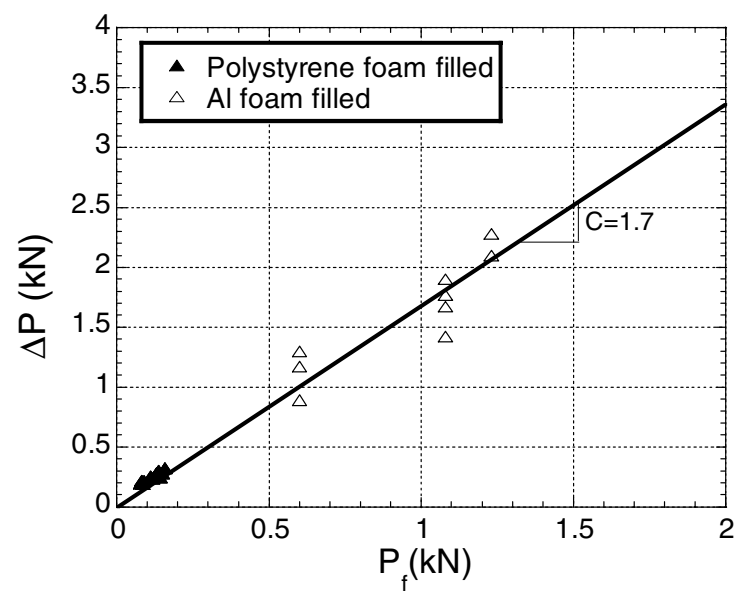

Fig. 9. The strengthening load vs. foam plateau load of $\mathrm{Al}$ and polystyrene foam filled tubes.

than the sum of the crushing loads of empty tube and foam, proving the interaction effect. The average crushing loads of tubes are calculated between the displacements 2 and $10 \mathrm{~mm}$ and shown by dotted lines in Fig. 7. Since at higher displacements, $>10 \mathrm{~mm}, \mathrm{Al}$ foam filler load increases sharply over the plateau load (Fig. 8).

The strengthening load $(\Delta P)$, which was calculated by subtracting the average load of the filled tube from that of empty tube according to Eq. (2), can be expressed as function of foam plateau load $\left(P_{\mathrm{f}}\right)$ by the following equation:

$\Delta P=P_{\mathrm{af}}-P_{\mathrm{ae}}=C P_{\mathrm{f}}$.

The variation of strengthening load as function of foam plateau load is shown in Fig. 9 for the studies foam filled tubes. Linear interpolation to the data in this figure gives a strengthening coefficient of 1.7. This value of strengthening coefficient is very similar to the previously determined strengthening coefficient value for square $\mathrm{Al}$ tubes (1.8) [7]. It should also be noted that an average plateau load was used in Eq. (5) for polystyrene foam filler, but the use of plateau loads through $R$ and/or $W$ directions only slightly affected the strengthening coefficient $( \pm 5 \%)$.

\subsection{Analysis of energy absorption in foam filled tubes}

The energy absorption (EA) in filled tubes was simply calculated using the experimentally determined strengthening coefficient with the following equation:

$E A=\left(P_{\text {ae }}+C P_{\mathrm{f}}\right) \delta$.

The calculated energy absorption values using Eq. (6) and experimentally determined energy absorption values are shown in Fig. 10 as function of displacement for filled and empty tubes. The calculated energy absorption values of polystyrene foam filled and empty tubes show good agreements with the experiments. The increase in

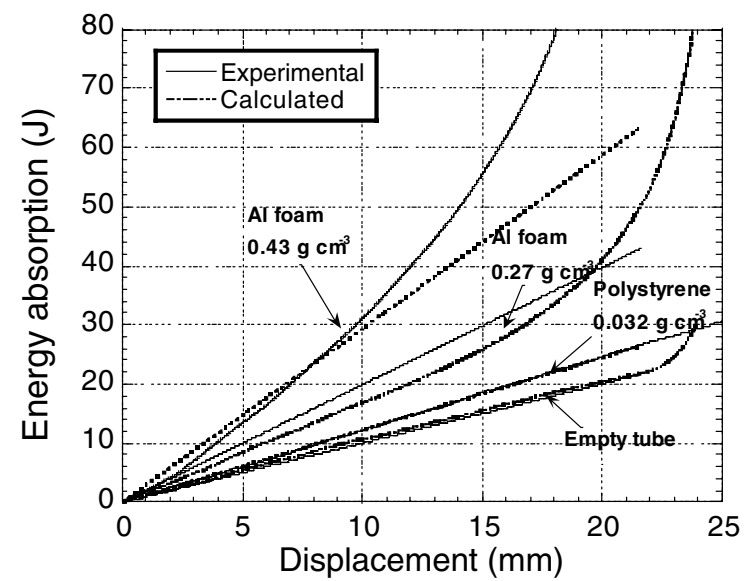

Fig. 10. Energy absorption as function of displacement in empty and foam filled Al tubes.

the load values of $\mathrm{Al}$ foam at larger displacements $(>10 \mathrm{~mm})$ over the plateau load however results in discrepancies between the calculated and experimental energy absorption values (Fig. 10).

It was previously shown that there is a critical total tube mass and the corresponding critical foam density above which the use of foam filling becomes more efficient than empty tube $[6,13]$. The critical total mass should be however determined using the tube wall-thickening of empty tube. Three plastic hinge models of Alexander [14], Singace et al. [15] and Wierzbicki et al. [16] were used to predict the average crushing load of the empty tube as function of the tube wall thickness. These models are given sequentially as:

$P_{\mathrm{a}}=\sigma_{0} t^{2}\left[8.462\left(\frac{R}{t}\right)^{1 / 2}+1.814\right]$,

$P_{\mathrm{a}}=\sigma_{0} t^{2}\left[7.874\left(\frac{R}{t}\right)^{1 / 2}+1.408\right]$,

$P_{\mathrm{a}}=11.22 \sigma_{0} t^{2}\left(\frac{R}{t}\right)^{1 / 2}$,

where $\sigma_{0}, t$ and $R$ are the mean stress from yield point to failure, thickness and mean tube radius, respectively. The value of $\sigma_{0}$ for the studied tube material was determined from the tension tests and found nearly $135 \mathrm{MPa}$. In the calculations, the inner radius of the tube was taken as constant $(12.21 \mathrm{~mm})$ while the thickness of the tube increased from 0.29 to $6 \mathrm{~mm}$. The calculated specific energy absorption of empty tubes using Eqs. (7)(9) is shown in Fig. 11 as a function of total mass of the tube. For the tested empty tube, Eq. (9) estimates well the specific energy absorption and, therefore, calculations of $\mathrm{Al}$ foam filled tube specific energies were based on the average crushing load of the tube estimated by Eq. (9). Foam filling along with an adhesive was 


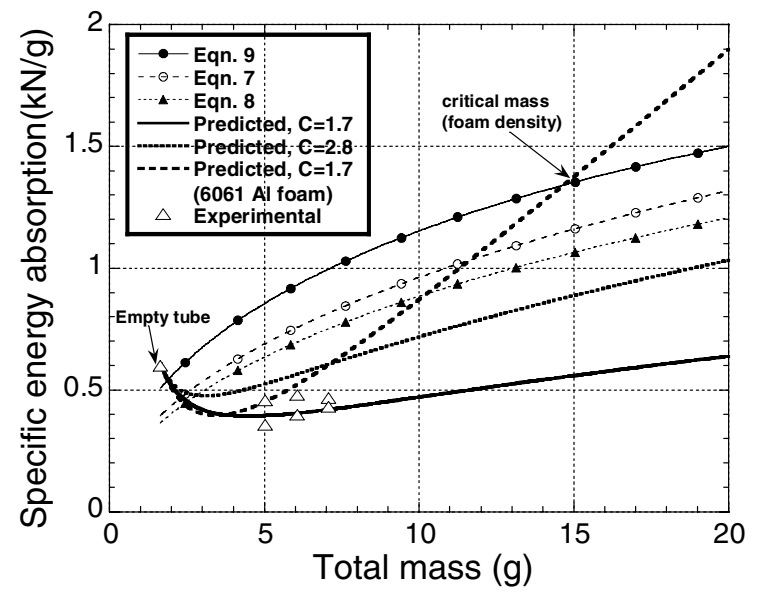

Fig. 11. Predicted and experimental specific energy absorption vs. total mass of empty and $\mathrm{Al}$ foam filled tubes.

previously shown to be used to tailor the specific energy absorption capacity of the filled tubes by increasing the level of interaction effect. The use of adhesive can contribute to the specific energy absorption of the tube by two mechanisms, namely, increased load transfer from tube wall to the foam core and peeling of the adhesive. The value of $C$ in the bonded case (adhesive) was found to be 2.8 [7]. Using Eq. (2) with $C$ values corresponding to bonded and unbonded cases, Eq. (9) for the empty tube average crushing load and Eq. (4) for the Al foam plateau load, the specific energy absorptions of $\mathrm{Al}$ foam filled tubes were calculated and also plotted as function of total mass in Fig. 11. It can be inferred from Fig. 11 that within the investigated wall thickness range, for bonded and unbonded cases, there appears no critical total mass (or Al foam density) above which the foam filling is more favorable than thickening of the tube wall. This is partly due to relatively low plateau stresses of $\mathrm{Al}$ foam studied. In order to estimate the effect of increasing foam plateau stress on the specific energy absorption, the parameters of Eq. (4) were changed for a stronger $\mathrm{Al}$ foam, $6061 \mathrm{Al},(K=22.4(\mathrm{MPa})$ and $n=1.99$ ), which was previously studied by Toksoy et al. [13]. The predicted specific energy absorption of $6061 \mathrm{Al}$ foam filling for unbound case is also shown in Fig. 11. In this case, the critical mass and hence foam density $\left(0.6 \mathrm{~g} \mathrm{~cm}^{-3}\right)$ is clearly seen in Fig. 11 , proving the effect of foam plateau load on the efficiency of foam filling. A similar critical total mass has been previously found in $\mathrm{Al}$ foam filled tubes $[6,13]$.

The present experimental results and predictions of energy absorptions using the strengthening coefficient of foam filling clearly demonstrate, although foam filling resulted in a higher energy absorption than the sum of the energy absorptions of the tube alone and foam alone, it might be not always more effective in increasing the specific energy than simply thickening the tube walls. Therefore, for efficient foam filling an appropriate foam- tube combination must be selected by considering the magnitude of strengthening coefficient of foam filling and the foam filler plateau load.

\section{Conclusions}

An experimental study was conducted on the strengthening coefficient of $\mathrm{Al}$ and polystyrene foam filling in a thin-walled $\mathrm{Al}$ tube in order to analyze energy absorption in filled tubes. Based on experimental results and predictions, followings can be concluded:

1. In the studied foam density range, regardless the foam type and density used, foam filling changed the deformation mode of empty tube from diamond to concertina.

2. The strengthening coefficient of foam filling was experimentally determined to be 1.7 , which was very similar to the previously determined strengthening coefficient for $\mathrm{Al}$ foam filled square $\mathrm{Al}$ tubes.

3. Although foam filling resulted in higher energy absorption than the sum of the energy absorptions of the tube alone and foam alone, it was found to be not more effective in increasing the specific energy than simply thickening the tube walls. For effective foam filling, an appropriate tube-foam combination must be selected by considering the magnitude of strengthening coefficient of foam filling and the plateau load of foam filler.

\section{Acknowledgement}

The authors thank the Scientific and Technical Council of Turkey (TUBITAK) for the Grant \# MISAG-227.

\section{References}

[1] Seitzberger M, Rammerstorfer FG, Degischer HP, Grandiger R. Crushing of axially compressed steel tubes filled with aluminium foam. Acta Mech 1997;125:93-105.

[2] Hanssen AG, Langseth M, Hopperstad OS. Static and dynamic crushing of circular aluminium foam filler. Int J Impact Eng 2000;24:475-507.

[3] Seitzberger M, Rammerstorfer FG, Gardinger R, Degischer HP, Blaimschein M, Walch C. Experimental studies on the quasi-static axial crushing of steel columns filled with aluminium foam. Int $\mathbf{J}$ Solids Struct 2000;37:4125-47.

[4] Hanssen AG, Langseth M, Hopperstad OS. Static and dynamic crushing of square aluminium extrusions with aluminium foam filler. Int J Impact Eng 2000;24:347-83.

[5] Guillow SR, Lu G, Grezbieta RH. Quasi-static axial compression of thin-walled circular aluminium tubes. Int $\mathbf{J}$ Mech Sci 2001;43:2103-23.

[6] Santosa SP, Wierzbicki T. Crash behavior of box columns filled with aluminum honeycomb or foam. Comput Struct 1998;68: 343-67. 
[7] Santosa SP, Wierzbicki T, Hanssen AG, Langseth M. Experimental and numerical studies of foam-filled sections. Int J Impact Eng 2000;24:509-34.

[8] Singace AA. Collapse behaviour of plastic tubes filled with wood sawdust. Thin-Walled Struct 2000;37:163-87.

[9] Hanssen AG, Langseth M, Hopperstad OS. Optimum design for energy absorption of square aluminium columns with aluminium foam filler. Int J Mech Sci 2001;43:153-76.

[10] Hall IW, Ebil O, Guden M, Yu CJ. Quasi-static and dynamic crushing of empty and foam filled tubes. J Mater Sci 2001;36:5853-60.

[11] Baumeister J, Schrader H. US Patent No. 51512461992.

[12] Elbir S, Yilmaz S, Toksoy AK, Guden M, Hall IW. SiCparticulate aluminum composite foams produced by powder compacts: foaming and compression behavior. J Mater Sci 2003;38:4745-55

[13] Toksoy AK, Tanoglu M, Guden M, Hall IW. Effect of adhesive on the strengthening of aluminum foam-filled circular tubes. J Mater Sci 2004;39:1503-6.

[14] Alexander JM. An approximate analysis of the collapse of thin cylindrical shells under axial loading. Q J Mech Appl Math 1960;13:10-5.

[15] Signace AA, Elbosky H, Reddy TY. On the eccentrity factor in the progressive crushing of tubes. Int $\mathbf{J}$ Solids Struct 1995;32:3589-602.

[16] Wierzbicki T, Bhat SU, Abramowicz W, Brodkin D. Alexander revisited - a two folding elements model of progressive crushing of tubes. Int J Solids Struct 1992;29:3269-88. 